\title{
Dual-tasking attenuates the return of fear after extinction
}

Citation for published version (APA):

Leer, A., Engelhard, I. M., Dibbets, P., \& van den Hout, M. A. (2013). Dual-tasking attenuates the return of fear after extinction. Journal of Experimental Psychopathology, 4(4), 325-340.

https://doi.org/10.5127/jep.029412

Document status and date:

Published: 01/01/2013

DOI:

10.5127/jep.029412

Document Version:

Publisher's PDF, also known as Version of record

Document license:

Taverne

Please check the document version of this publication:

- A submitted manuscript is the version of the article upon submission and before peer-review. There can be important differences between the submitted version and the official published version of record.

People interested in the research are advised to contact the author for the final version of the publication, or visit the DOI to the publisher's website.

- The final author version and the galley proof are versions of the publication after peer review.

- The final published version features the final layout of the paper including the volume, issue and page numbers.

Link to publication

\footnotetext{
General rights rights.

- You may freely distribute the URL identifying the publication in the public portal. please follow below link for the End User Agreement:

www.umlib.nl/taverne-license

Take down policy

If you believe that this document breaches copyright please contact us at:

repository@maastrichtuniversity.nl

providing details and we will investigate your claim.
}

Copyright and moral rights for the publications made accessible in the public portal are retained by the authors and/or other copyright owners and it is a condition of accessing publications that users recognise and abide by the legal requirements associated with these

- Users may download and print one copy of any publication from the public portal for the purpose of private study or research.

- You may not further distribute the material or use it for any profit-making activity or commercial gain

If the publication is distributed under the terms of Article $25 \mathrm{fa}$ of the Dutch Copyright Act, indicated by the "Taverne" license above, 
See discussions, stats, and author profiles for this publication at: https://www.researchgate.net/publication/262376247

\section{Dual-Tasking Attenuates the Return of Fear after Extinction}

Article in Journal of Experimental Psychopathology · January 2013

DOI: $10.5127 /$ jep.029412

\section{CITATIONS}

11

4 authors, including:

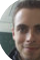

Arne Lee

Utrecht University

21 PUBLICATIONS 491 CITATIONS

SEE PROFILE

Q7) Pauline Dibbets

Maastricht University

44 PUBLICATIONS 616 CITATIONS

SEE PROFILE

Some of the authors of this publication are also working on these related projects:

Fear of COVID-19 View project

Project Effects of verbal instructions in human fear conditioning View project
220 PUBLICATIONS 6,351 CITATIONS

SEE PROFILE 


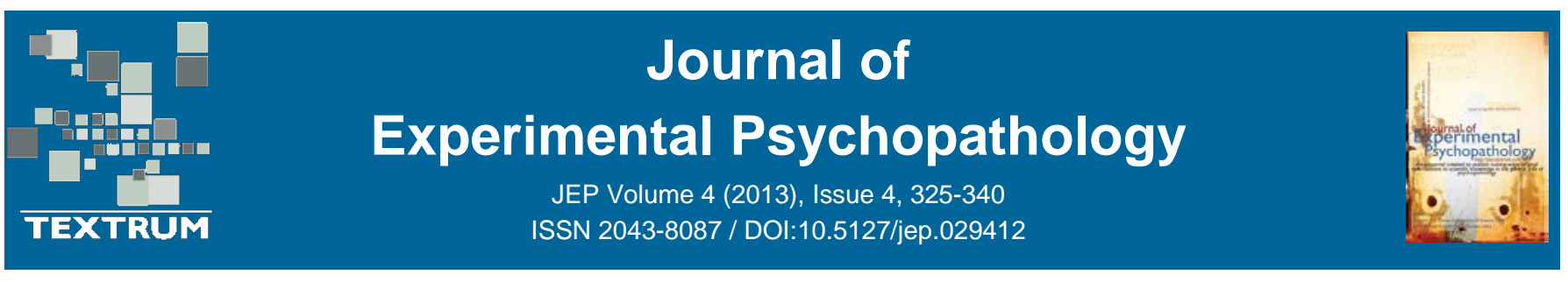

\title{
Dual-Tasking Attenuates the Return of Fear after Extinction
}

\author{
Arne Leer ${ }^{a}$, Iris M. Engelhard ${ }^{a}$, Pauline Dibbets ${ }^{b}$, and Marcel A. van den Hout ${ }^{a}$ \\ ${ }^{a}$ Utrecht University, Utrecht \\ ${ }^{b}$ Maastricht University, Maastricht
}

\begin{abstract}
Return of fear following exposure treatment may be explained by ABA-renewal: fear acquired in context $A$, and extinguished in context $\mathrm{B}$, may return in context $\mathrm{A}$. Conditioning theory predicts that intensity of conditioned fear is mediated by the mental representation of the unconditioned stimulus (US) evoked by the conditioned stimulus (CS). This study tested whether US-devaluation via a dual-task - imagining the US while making eye movements attenuates fear renewal. Participants acquired fear in context A, and underwent extinction in context A or B. Next, two groups did a filler task (AAA; ABA), one a dual-task of US imagination with eye movements (ABA-DT), and one merely imagined the US (ABA-RO). Finally, participants were re-presented the CSs in context A. ABA-renewal was found for US-expectancy. Dual-tasking, but not recall only, reduced fear renewal. No between-group differences were observed in reductions of vividness, emotionality, and startle responses to the US. Findings suggest that dual-tasking may attenuate fear renewal.
\end{abstract}

(c) Copyright 2013 Textrum Ltd. All rights reserved.

Keywords: Dual-tasking; US-devaluation; Fear renewal; Extinction; Context; EMDR

Correspondence to: Arne Leer, Department of Clinical \& Health Psychology, Utrecht University, P.O. Box 80140, 3508 TC Utrecht, The Netherlands. Email: a.leer@uu.nl

1. Department of Clinical \& Health Psychology, Utrecht University, P.O. Box 80140, 3508 TC Utrecht, The Netherlands.

2. Department of Clinical Psychological Science, Maastricht University, P.O. Box 616, 6200 MD Maastricht, The Netherlands.

Received 25-May-2012; received in revised form 28-Jan-2013; accepted 28-Jan-2013 


\title{
Table of Contents
}

\author{
Introduction \\ Method \\ Participants \\ Stimuli \\ Outcome measures \\ US-expectancy \\ Cognitive US representation \\ Questionnaires \\ Procedure \\ Acquisition phase \\ Extinction phase \\ Test phase \\ Data preparation \\ Data reduction \\ Skin conductance responses \\ Startle responses \\ Results \\ US-expectancy \\ Self-report \\ Skin conductance responses \\ Change in the cognitive US representation \\ Discussion \\ Acknowledgements \\ References
}

\section{Introduction}

Exposure-based treatments are effective for anxiety disorders (Bisson et al., 2007; Chambless \& Ollendick, 2001; Deacon \& Abramowitz, 2004; Hofmann \& Smits, 2008), and involve exposure to the feared stimulus, which is the clinical analogue of a laboratory extinction procedure. This technique is based on the Pavlovian fear conditioning model, a widely accepted theory to explain the acquisition and extinction of fear (e.g., Deacon \& Abramowitz, 2004; Eysenck \& Martin, 1987; Mineka \& Oehlberg, 2008). In a typical fear conditioning experiment, a person learns to expect that a conditioned stimulus (CS) is followed by an aversive unconditioned stimulus (US), which causes the $\mathrm{CS}$ to elicit a conditioned response (CR; e.g., fear). During an extinction procedure, the CS is repeatedly presented in the absence of the US and, as a result, the CR gradually diminishes. However, conditioned fear may (partly) return after it has weakened or extinguished (e.g., Hermans, Craske, Mineka, \& Lovibond, 2006). Clinical data demonstrate considerable relapse rates after exposure treatment (e.g., social phobia: 13\%; Fava, Grandi et al., 2001; panic disorder: 23\%: Fava, Rafanelli et al., 2001; obsessive-compulsive disorder: 11\%; Simpson et al., 2004). Therefore, strategies that challenge the return of fear are needed to boost treatment success.

Phenomena that give rise to the return of fear have been identified (for reviews, see Bouton, 2002, 2004; Hermans et al., 2006). Fear may return as time passes (spontaneous recovery) or in response to presentations of the US only (reinstatement). Additionally, a context switch after extinction can result in return of fear, which is known as renewal of fear. Typically, in these experiments, fear conditioning takes place in one context ("Context A"; e.g., lit room) and extinction learning takes place in another context ("Context B"; e.g., dimmed room). When CSs are presented again in context A, fear returns (ABA-renewal; Bouton \& King, 1983). This phenomenon has proven to be robust in (sub)clinical samples (e.g., Mineka, Mystkowski, Hladek, \& Rodriguez, 1999; Mystkowski, Craske, \& Echiverri, 2002) and student samples (Effting \& Kindt, 2007; Neumann \& Kitlertsirivatana, 2010; Vansteenwegen et al., 2005). Strategies countering fear renewal include extinction in multiple contexts (e.g., Balooch \& Neumann, 2011; Vansteenwegen et al., 2007; but see Bouton, García-Gutiérrez, Zilski, \& Moody, 2006) and using retrieval cues for extinction (e.g., Dibbets \& Maes, 2011; Vansteenwegen et al., 2006). These methods capitalize on 
changing the predictive quality of the CS (i.e., reducing US-expectancy), which may have a significant drawback: the original fear memory may be retrieved under particular circumstances.

Researchers have hypothesized that during extinction the original fear memory (CS-US) is not destroyed or unlearned (Bouton, 2002; Delamater, 2004; Hermans et al., 2006). Instead, as supported by animal research (Delamater, 1996; Rescorla, 1996), a new association (CS-no US) is formed that renders the old CS-US association less salient. Expression of this new association depends directly on the context in which the CS is encountered (as evidenced by the renewal phenomenon). Thus, after an extinction procedure, confrontation with the CS outside the extinction context seems to reactivate the original fear memory, which incites renewal of fear. Context-dependency of conditioned responding would not be a problem if pathological fear would involve only a single context. However, multiple contexts are likely to play a role in fear conditioning (e.g., Craske et al., 2008). Practically, this implies that all significant contexts and CSs should be considered in treatment to successfully prevent relapse, which may not be feasible.

An alternative method to reduce fear renewal may be to devaluate the cognitive representation of the US, such that it becomes less aversive. Davey's (1997) classical conditioning model stresses that CR strength is not just a function of the strength of the learned CS-US association, but also of the mental US representation. Thus, revaluation of the cognitive representation of the US may occur independently of any changes in the CS-US association, and such US revaluation will mediate change in CR strength. For example, mere exposure to the actual US may weaken the CR (i.e., habituation; Davey \& McKenna, 1983), and (ruminative) cognitive rehearsal of the US may strengthen the CR (Jones \& Davey, 1990). Since changes in the US representation are less likely to be context-dependent, it is both theoretically and clinically important to examine whether fear renewal can be reduced by US-devaluation.

Previous studies provide tentative support for this hypothesis. For example, in rats, habituation to the US reduces fear renewal (Rauhut, Thomas, \& Ayres, 2001). In humans, US-devaluation via imagery rescripting (IR; an effective treatment for various anxiety disorders; Holmes \& Mathews, 2010) has been used to attempt to reduce the renewal effect (Dibbets, Poort, \& Arntz, 2012). During IR, a mental image of the aversive US is verbally rescripted into a more acceptable image. Dibbets and colleagues hypothesized that IR of the US reduces fear renewal. They administered a fear conditioning paradigm to undergraduates. Fear acquisition took place in context $A$, in which a $\mathrm{CS}+$ (picture of a car), but not a CS- (picture of a motorcycle) was followed by a US (picture of a mutilated dead child). During extinction, only the CS+ and CS- were presented. Four extinction conditions were used: (1) for an AAA group, extinction took place in context $A,(2)$ for an ABA group, extinction took place in context $B$, (3) for an ABA-IR group, extinction was in context $B$ and was accompanied by IR, and (4) for an ABA-IUn group, extinction was in context $B$ and was accompanied by imagery unrelated to the US. Finally, a testing phase involved CS presentations in context A. The main findings were that the ABA-IR group showed both US-devaluation and less renewal of US-expectancy ratings, suggesting that the US representation had changed. Although these results were promising, there might have been a confounding factor. In the ABA-IR group, significantly less extinction took place than in the other groups, presumably because participants rehearsed the CS-US association as a part of IR during the extinction trials. Therefore, any conclusions on the renewal of fear may be premature.

The current study will focus on another potential US-devaluation technique, which involves a dual-task approach. In this type of task, a person keeps the US image in mind while, at the same time, attending to an external stimulus. In clinical and laboratory studies such a dual-task typically involves induction of horizontal eye movement (EM; e.g., by visually tracking a circle that moves from side to side across a computer screen). Analogue laboratory studies have shown that EM during recall of an emotional image renders the image less vivid and/or emotional during future recollections, compared to recall alone (e.g., Engelhard, van den Hout, Janssen, \& van der Beek, 2010; Engelhard, van den Hout, \& Smeets, 2011; Gunter \& Bodner, 2008; Maxfield, Melnyk, \& Hayman, 2008; van den Hout et al., 2011). These findings agree with clinical data showing that Eye Movement Desensitization and Reprocessing (EMDR) therapy is effective for treating posttraumatic stress disorder (PTSD, e.g., Bisson et al., 2007), and that the EM component adds to its beneficial effects (Lee \& Cuijpers, 2013). The effectiveness of EM can be explained by a working memory (WM) theory: as WM is limited, any taxing task during mental imagery competes for storage capacity or rehearsal processes and, therefore, disrupts mental imagery. As a result the vividness and emotionality of the mental representation decrease (e.g., Gunter \& Bodner, 2008). 
There is experimental support for the effectiveness of other competing tasks (e.g., drawing a complex figure [Gunter \& Bodner, 2008], or counting backwards [Engelhard et al., 2011]), but most studies have used EM and repeatedly provided evidence for its effectiveness. Therefore, based on its reliability, we used EM as the competing task in the current study. Importantly, the beneficial effects of EM have, by and large, been demonstrated for visual memories (i.e., autobiographic material, e.g., Gunter \& Bodner, 2008; or images provided by the investigator, e.g. Andrade, Kavanagh, \& Baddeley, 1997). Hence, we decided to investigate fear conditioning with an aversive picture as US (cf. Dibbets et al., 2012) instead of a more traditional electrocutaneous or loud auditory stimulus (e.g. Lipp, 2006). Usually, picture-picture conditioning paradigms are used to investigate evaluative conditioning - the acquisition of likes and dislikes (De Houwer, Thomas, \& Baeyens, 2001). However, several studies have demonstrated differential skin conductance responses (SCRs) - a physiological signature of fear - in picturepicture paradigms with aversive pictures as US (e.g., Dawson, Rissling, Schell \& Wilcox, 2007; Klucken et al. 2009).

The main objective of the present study was to examine whether recall of a US while making EM leads to less ABA-renewal. To test the hypothesis, four conditions were used. Two conditions were included to demonstrate fear renewal (AAA vs. ABA). In the third condition the dual-task was used between extinction and a test phase (ABADT). The fourth condition was added to explore the effect of imaginary exposure, in which the dual-task was replaced by mere imagery (recall only: ABA-RO). US devaluation was assessed by memory vividness and emotionality ratings. In addition, we measured potentiated startle during imagery as startle augmentation has been observed during imagery of unpleasant scripts (e.g., Miller, Patrick, \& Levenston, 2002) and startle diminution has been observed after dual-tasking (Engelhard, van Uijen, \& van den Hout, 2010).

\section{Method}

\section{Participants}

A total of 109 Utrecht University students enrolled in this study. A priori, we decided to include 20 in each condition, with the requisite that each participant acquired the CS-US contingency and showed extinction (see Data reduction). Further exclusion criteria were: knowledge of EMDR and prior participation in research on EMDR. The final sample involved 80 participants (61 women; $M$ age $=21.97, S D=2.93$ ).

\section{Stimuli}

CSs were pictures of a black triangle and a black square with a width and height of approximately $7.5 \mathrm{~cm}$. CSs were presented against a brightly colored background (yellow or cyan) that served as context and was manipulated as a function of experimental phase and condition. The US was a picture of a mutilated dead child (IAPS picture 3051; cf. Dibbets et al., 2012) that covered $75 \%$ of the screen, which allowed participants to perceive the contextual background color. Dibbets and colleagues (2012) showed that this picture serves a useful US: SelfAssessment-Manikin ratings indicated that participants evaluated this picture as highly unpleasant. Moreover, the US-picture received significantly larger SCR than did both CS-pictures at first presentation. The experimental paradigm was presented with E-Prime 2.0 (Psychology Software Tools).

\section{Outcome measures}

\section{US-expectancy}

US-expectancy was assessed with a question ('to what degree do you expect the aversive picture of the child now') rated on a Visual Analogue Scale (VAS) on the screen that ranged from 0 (= not at all) to 100 (= definitely). Anticipation of the US was also measured with SCR that was registered with a Coulbourn Modular Instruments System (Allentown, PA, USA) via a Coulbourn Isolated Skin Conductance coupler (S71-23). A constant current of $.5 \mathrm{~V}$ was transmitted via 9-mm Sensor Medics $\mathrm{Ag} / \mathrm{AgCl}$ electrodes that were attached to the medial phalanges of the middle and index finger (cf. Fowles et al., 1981). 


\section{Cognitive US representation}

Quality of the cognitive US representation was examined with three VASs for emotional intensity $(0=$ not at all unpleasant, $100=$ extremely unpleasant), vividness $(0=$ not at all vivid, $100=$ extremely vivid $)$, and difficulty recalling the image $(0=$ not at all difficult, $100=$ extremely difficult $)$, and with startle responses. Loud tones $(50 \mathrm{~ms}$, $95 \mathrm{~dB}$ ) with instant rise and fall time served as startle probes and were presented through headphones. Electromyographic (EMG) activity was recorded with two 4-mm Sensor Medics Ag/AgCl electrodes placed over the orbicularis oculi region of the right eye. A 9-mm ground electrode was placed in the middle of the forehead. The raw EMG signal, sampled at 1,000 Hz, was amplified $(10 \mathrm{~K})$ and filtered (13 Hz high-pass; $150 \mathrm{~Hz}$ low-pass) by a Coulbourn V75-04 Isolated Bioamplifier with Bandpass Filter (Blumenthal et al., 2005; cf. Engelhard, van Uijen et al., 2010).

\section{Questionnaires}

Neuroticism was assessed with the 22 neuroticism items of the Eysenck Personality Questionnaire (EPQ; Eysenck \& Eysenck, 1975; Sanderman, Arrindell, Ranchor, Eysenck, \& Eysenck, 1995) using the binary response format ( $0=$ no, 1=yes). Items from the extraversion scale were administered as well, and were mixed with the neuroticism items, to minimize order-related artifacts (e.g., adopting a negative response tendency).

State and trait anxiety were assessed with the State Trait Anxiety Inventory (STAI-DY; Spielberger, Gorsuch, \& Lushene, 1970; Van der Ploeg, Defares, \& Spielberger, 1980) that consists of 20 items measuring state anxiety ( $\alpha$ $=.86$ in current study) and 20 measuring trait anxiety ( $\alpha=.92$ in current study) scored on a 1-4-point scale $(1=$ not at all, $4=$ severely).

These questionnaires were included to control for differences across the conditions in levels of neuroticism and anxiety, as both constructs have been identified to affect fear conditioning (e.g., Grillon et al., 2006; Lissek et al., 2005).

\section{Procedure}

Participants were seated in a dim, soundproof room, approximately $60 \mathrm{~cm}$ in front of a computer screen. First, they received oral and written information. After signing informed consent, they filled out the questionnaires. Next, the skin was cleaned, electrodes were placed, and headphones were given. Each participant was randomly allocated to one of the four conditions: AAA, ABA, ABA-DT (dual-task), or ABA-RO (recall only).

\section{Acquisition phase}

Before acquisition, participants practiced rating the VAS, and were told to indicate their expectancy of the US by a mouse click on the scale, each time they saw a CS picture. All conditions underwent similar acquisition procedures in context A (yellow background), using 4 CS+ and 4 CS- trials. Each CS lasted for $6 \mathrm{~s}$, and only the CS+ was directly followed by the 2-s US. For the CS-, the intertrial interval (ITI) was extended by $2 \mathrm{~s}$. Order of CSs was pseudo randomized with a maximum of 2 similar CSs in succession. The 14-s CS-CS interval comprised a blank yellow screen. SCR was continuously recorded. The US-expectancy VAS was presented on the bottom of the screen during each CS. The instructions were to indicate during each CS-presentation, by means of a mouse-click on the VAS, to what degree the aversive picture was expected to follow the CS.

After the acquisition phase, participants were told: "Form an image of the mutilated child that you just saw a few times. Keep your eyes open and bring the image to mind as vividly as possible. Press the space bar when the image is vivid." Then, $11 \mathrm{~s}$ after the space bar was pressed, participants were asked to rate vividness, emotionality, and difficulty recalling the image, followed by the first startle measurement. Participants received 9 startle probes (mean interstimulus interval $=3 \mathrm{~s}$; range 2-4 s) to facilitate habituation. Next, instructions were to recall the image again and to ignore the probes as much as possible. After $500-2500 \mathrm{~ms}, 3$ startle probes (mean ITI $3.5 \mathrm{~s}$; range 2.5-4.5 s) were presented to elicit startle reflexes. This recall period (11 s) was repeated once, resulting in a total of 6 startle measurements. 


\section{Extinction phase}

The extinction phase involved context A (AAA: yellow background) or B (other groups: cyan background). Initially, all groups underwent a similar extinction phase, in which each CS was presented 6 times, without the US. Again, both US-expectancy and SCR were assessed. The instructions were to indicate to what degree the aversive picture was expected, and that if changes had occurred in the CS-US relationship, participants should translate this in their US-expectancy ratings. Subsequent to the extinction phase, all groups were instructed to recall the image of the US for $11 \mathrm{~s}$, and to rate image vividness and emotionality for the second time.

In the ABA-DT and ABA-RO groups, the distance between the participant and computer screen was reduced to 30 $\mathrm{cm}$. In ABA-DT, a black circle moved from left to right and back across the screen (at 1 cycle per $\mathrm{s}$ ) in context $B$ (cyan background). In ABA-RO, a stationary black circle was shown in the middle of the screen. Participants in these conditions were told to think of the image and watch the circle without moving their head at the same time. Both conditions comprised 6 sets of $24 \mathrm{~s}$, with $10 \mathrm{~s}$ breaks in between. The duration of these sets and breaks were based on the protocol used by others (e.g., Engelhard, van den Hout, Dek et al., 2011; Gunter \& Bodner, 2008; van den Hout, Muris, Salemink, \& Kindt, 2001). During this time, the other groups (AAA and ABA) did a filler task, in which 6 guitar pictures were shown twice. Participants were asked to indicate whether they saw each picture for the first or second time. To keep the duration of exposure to the contextual background identical over all groups, the filler task was displayed against the extinction background as well.

Finally, all groups were instructed to recall the US image again for $11 \mathrm{~s}$, and to rate image vividness and emotionality for the third time.

\section{Test phase}

All groups received a similar test phase in context A (yellow background). Both CSs were presented twice, with the restriction that the CS+ and CS- occurred in the first two trials, and the order was counterbalanced across conditions (cf. Dibbets et al., 2012). The procedure was comparable to the extinction phase. The instructions read: Again, please indicate to what degree you expect the aversive picture. Directly after the test phase, startle responses were measured again during US-imagination, which was identical to the first startle measurement after the acquisition phase.

\section{Data preparation}

\section{Data reduction}

Since this study used only two CSs and a 100\% contingency between the CS+ and US in the acquisition phase, participants unaware of the CS-US contingency were considered to be inattentive or having insufficient understanding of the experimental procedure (cf. Dibbets et al., 2012). Moreover, drawing conclusions on the renewal of fear is only appropriate when both fear acquisition and fear extinction are verified. Therefore, participants were only included in data analyses when their US-expectancy score at the final acquisition trial was at least 70 for the CS+ and less than 30 for the CS-. At the final extinction trial, US-expectancy scores for both CSs needed to be less than 30. Based on these criteria, 29 participants were excluded from analyses, resulting in a final sample of 80 participants. Due to 1 missing value in the ABA group, renewal of US-expectancy was analyzed using 79 participants.

\section{Skin conductance responses}

Responses were calculated by subtracting the mean SC level for the $2 \mathrm{~s}$ preceding CS onset from the largest value recorded during the full 6-s CS interval (cf. Pineles, Orr, \& Orr, 2009). The minimum response amplitude was set at $.05 \mu \mathrm{S}$ (Dawson, Schell, \& Filion, 2000). All other responses were scored as 0 and left in the analyses. After applying a square root transformation to all SCR data, no outliers were found. Finally, an individual range correction (SCR/SCR $\max$ ) was used to minimize interindividual variance (Lykken \& Venables, 1971). 


\section{Startle responses}

Response amplitudes were computed as the difference between the maximum EMG value within 20 to $150 \mathrm{~ms}$ after stimulus onset and the average EMG value during baseline ( -40 to $+10 \mathrm{~ms}$ around stimulus onset). Response onset latency was set at 21-80 ms (Blumenthal et al., 2005). All obtained amplitudes were transformed by square root. Next, an individual range correction was applied by standardizing each blink amplitude using all scores for a given subjects as the reference distribution (Blumenthal et al., 2005; cf. Grillon \& Baas, 2003). To this end, T scores were calculated $(50+10 *[($ raw score $-M) / S D])$. For each group separately, outliers were replaced by $M \pm$ 2.5 SD. Finally, following the Blumenthal et al. (2005) recommendation, mean response magnitudes for the 6 trials per block were calculated by the product of the mean amplitude of all detected responses and response probability (i.e., ratio detected responses / elicited responses).

\section{Results}

In the following analyses, when the sphericity assumption was violated, Greenhouse-Geisser or Huynh-Feldt corrections were applied. In post-hoc t-tests Bonferroni corrections were applied.

Table 1 shows the data for background variables. No differences were found between the four experimental conditions in age $(F<1)$, neuroticism scores, $F(3,75)=2.38, p=.08$, state anxiety, $F(3,76)=1.91, p=.14$, or trait anxiety, $F(3,75)=1.26, p=.30$. Furthermore, gender ratio was comparable over conditions, $\chi^{2}(3)=1.31, p=.73$.

Table 1: Mean (SD) and ratio for demographic information and questionnaire data

\begin{tabular}{lccccc}
\hline Group & Age & F/M & Neuroticism & Trait anxiety & State anxiety \\
\hline AAA & $22.45(3.50)$ & $15 / 5$ & $8.37(5.96)$ & $36.90(11.15)$ & $32.95(7.06)$ \\
ABA & $21.75(2.71)$ & $15 / 5$ & $6.35(4.07)$ & $34.05(7.18)$ & $32.30(6.01)$ \\
ABA-DT & $21.45(2.72)$ & $17 / 3$ & $6.60(5.02)$ & $37.65(10.21)$ & $35.05(6.11)$ \\
ABA-RO & $22.25(2.85)$ & $14 / 6$ & $10.00(4.57)$ & $39.60(6.75)$ & $37.05(8.45)$ \\
\hline
\end{tabular}

\section{US-expectancy}

\section{Self-report}

First, US expectancies during CS+ and CS- were examined separately for the acquisition and extinction phases. Then, renewal of US-expectancy was studied in the test phase. Figure 1 illustrates differential responding over time, for each condition.

For the acquisition phase, a 2 (CS type: CS+ vs. CS-) $\times 4$ (Trial) $\times 4$ (Condition: AAA vs. ABA vs. ABA-DT vs. ABA-RO) ANOVA showed main effects for CS type, $F(1,76)=744.02, p<.001$, and Trial, $F(2.39,181.88)=$ $15.39, p<.001$, with US expectancies for the CS+ being overall higher than for the CS-, and increasing over time. There was no main effect for condition, $F<1$. There was a significant CS type $\times$ Trial interaction, $F(2.25,170.80)=$ $245.38, p<.001$, but the CS type $\times$ Trial $\times$ Condition interaction was not significant, $F<1$. Post hoc paired $t$-tests comparing US expectancies at the first and last acquisitions trials, showed that over time US-expectancy increased for CS+, $t(79)=12.48, p<.001$, and decreased for CS-, $t(79)=20.02, p<.001$, indicating differential learning over time. Crucially, US expectancies were higher during the last CS+ trial compared to during the last CS- trial, $F(1$, 76) $=4379.39, p<.001$, which did not differ across conditions, $F<1$.

The extinction phase demonstrated main effects for CS type, $F(1,76)=5.96, p<.05$, and Trial, $F(2.62,199.26)=$ $212.51, p<.001$, with US expectancies being overall higher for CS+ than CS-, and decreasing over time. There was no main effect for condition, $F(3,76)=1.84, p=.15$. The CS type $\times$ Trial interaction was significant, $F(2.35$, $178.25)=5.65, p<.01$, which can be explained by higher US expectancies during CS + than CS - at the first extinction trial, $t(79)=3.01, p<.01$. Furthermore, the three-way interaction was not significant, $F(7.04,178.25)=$ $1.35, p=.23$. Crucially, US expectancies were similar during the last CS+ trial compared to the last CS- trial, $F<1$, which did not differ across the conditions, $F(3,76)=1.67, p=.18$. Therefore, differences between the conditions in the renewal of US-expectancy can be attributed to the intervention that followed the extinction phase. 

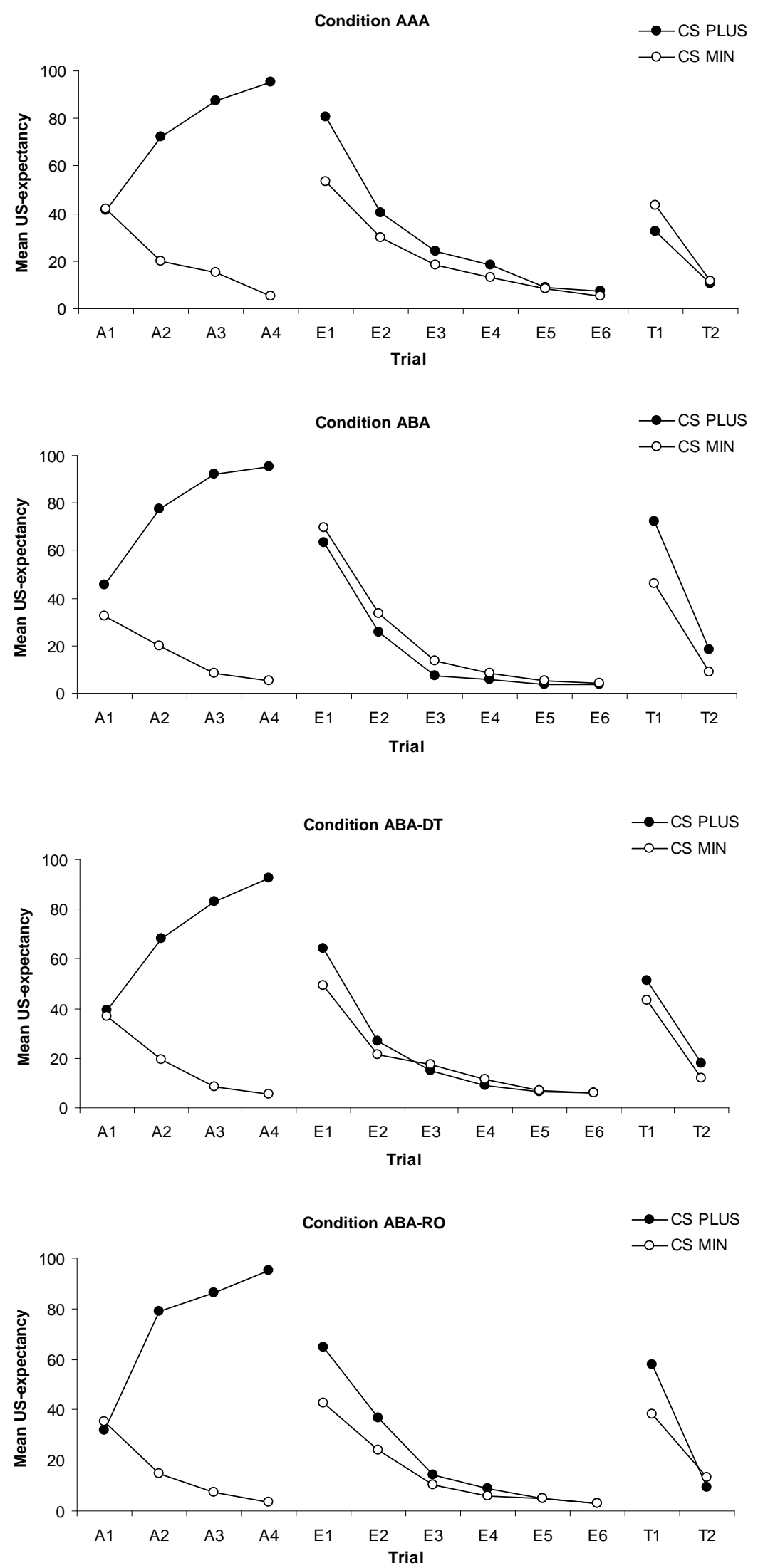

Figure 1: Mean US-expectancy for CS+ and CS- during acquisition (trials A1-A4), extinction (trials E1-E6), and test (trial T1 and T2).

Renewal of US-expectancy was examined by comparing ratings at the last extinction trial to the first test trial in a CS type $\times$ Trial $\times$ Condition ANOVA. All main effects and two-way interaction effects were significant at $p<.05$, 
except for the main effect of Condition, $F(3,75)=1.80, p=.15$. Importantly, the three-way interaction was significant, $F(3,75)=5.94, p<.01$, indicating that differential responding over time differed between conditions.

To test the hypotheses, separate CS type $\times$ Trial $\times$ Condition ANOVAs were performed that directly compared the conditions of interest. First, an ANOVA that compared conditions AAA and ABA revealed a significant three-way interaction, $F(1,37)=14.70, p<.001$. To break down this three-way interaction, separate CS type $\times$ Trial ANOVAs were performed. For AAA, the interaction effect was not significant, $F(1,19)=3.42, p=.08$, meaning that change in US-expectancy over time was similar for CS- and CS+. For ABA, there was a significant interaction effect, $F(1$, $18)=12.15, p<.001$. Post-hoc $t$-tests showed that US-expectancy increased over time for both CS,$- t(19)=7.78$, $p<.001$, and CS $+t(18)=13.77, p<.001$. Crucially, this increase was larger for CS + than for CS $-, t(19)=3.49, p$ $<.01$, serving a proof of principle for ABA renewal.

Next, to test the main hypothesis, conditions ABA and ABA-DT were compared. The ANOVA revealed a significant three-way interaction, $F(1,37)=3.33, p<.05$, meaning that differential responding over time differed between the conditions. To further understand ABA-DT, a separate CS type $\times$ Trial ANOVA was conducted for this condition. This analysis revealed that the interaction effect was not significant, $F(1,19)=1.81, p=.19$, indicating that, in line with the hypothesis, there was no renewal of US-expectancy in ABA-DT.

Finally, conditions ABA and ABA-RO were compared. The three-way interaction was not significant, $F<1$, showing that differential responding over time did not differ between these conditions. A separate CS type $\times$ Trial ANOVA for ABA-RO yielded a significant interaction effect, $F(1,19)=7.28, p<.05$. Post-hoc $t$-test showed that USexpectancy increased over time for CS-, $t(19)=5.74, p<.001$, and CS+, $t(19)=8.14, p<.001$, and that this increase was larger for CS+ than for CS-, $t(19)=2.70, p<.05$. These analyses suggest that there was renewal of US-expectancy in both ABA and ABA-RO. However, a direct comparison between conditions ABA-DT and ABA-RO did not yield a three-way interaction, $F(1,38)=1.34, p=.26$.

In sum, $A B A$-renewal was found. Extinguished fear returned in condition $A B A$, but not in condition $A A A$. In line with the hypothesis, fear renewal was absent in condition ABA-DT. Lastly, there was differential responding over time in ABA-RO, but this condition did not differ significantly from either ABA-DT or ABA.

\section{Skin conductance responses}

\section{US aversiveness}

To assess whether the employed US elicited a physiological response, indicative of fear, a 3 (Stimulus: CS-, CS+, US) $\times 4$ (Condition) ANOVA was conducted on SCR to the first presentation of each stimulus. This analysis only yielded a significant main effect of Stimulus, $F(1.78,126.63)=12.63, p<.001$. Post-hoc comparisons showed that SCR was larger in response to the US $(M=.027, S D=.042)$ than to CS- $(M=.008, S D=.022), t(74)=4.01, p<$ .001 , and CS+ $(M=.010, S D=.023), t(78)=3.80, p<.001$, but CS + and CS- did not differ from each other, $t<1$ (cf. Dibbets et al., 2012; note that the relatively low mean values are the result of transformations).

\section{Differential conditioning}

The percentage of participants with elevated SCR (larger than $.05 \mu \mathrm{S}$ ) to the CS+ was $17.0 \%$ during acquisition, $6.7 \%$ during extinction, and $7.7 \%$ during the test phase. Due to the minority of participants providing useful data we will report but not interpret the results. A 2 (CS type) $\times 4$ (Condition) ANOVA on average SCR was conducted, for each experimental phase. During acquisition, SCR was higher for CS+ than for CS-, $F(1,76)=4.71, p<.05$. This difference was absent during extinction, $F<1$, and did not reach significance during test, $F(1,76)=2.10, p=.15$. No between-group differences were present in any phase.

\section{Change in the cognitive US representation}

No differences were observed between the conditions in difficulty recalling the US-image $(M=23.02, S D=18.63)$, $F<1$. Self-reported vividness and emotional intensity of the recalled US memory were analyzed for the three time points: (1) post-acquisition, (2) pre-intervention (i.e., after extinction, but before the dual-task, recall only, or filler 
task), and (3) post-intervention. The first measurement served as baseline. In line with expectations, no group differences were present at the baseline or pre-intervention for vividness, $F_{\text {baseline }}(3,76)=1.34, p=.27, F_{\text {pre- }}$ intervention $(3,76)=1.27, p=.29$, or emotionality: $F S<1$. Notably, substantial reductions between the first two measurements (in the course of extinction) were observed for both vividness and emotionality (see Figure 2).

To examine the effects of each intervention, two separate 2 (Time: pre-intervention vs. post-intervention) $\times 4$ (Condition: AAA vs. ABA vs. ABA-DT vs. ABA-RO) ANOVAs were conducted. For vividness ratings, there was a main effect of time, $F(1,76)=7.82, p<.01$, with ratings decreasing over time. There was no significant main effect of condition, $F(3,76)=1.89, p=.14$, and no interaction effect, $F<1$, meaning that the reductions over time were similar across the four conditions. Similarly, for emotionality ratings, there was a main effect of time, $F(1,76)=$ $21.90, p<.001$, with ratings decreasing over time, but no significant main effect of condition, $F(3,76)=1.52, p=$ .22 , and no interaction effect, $F<1$. Note, however, that the reductions in the course of intervention are subordinate to the reductions in the course of extinction (Figure 2).

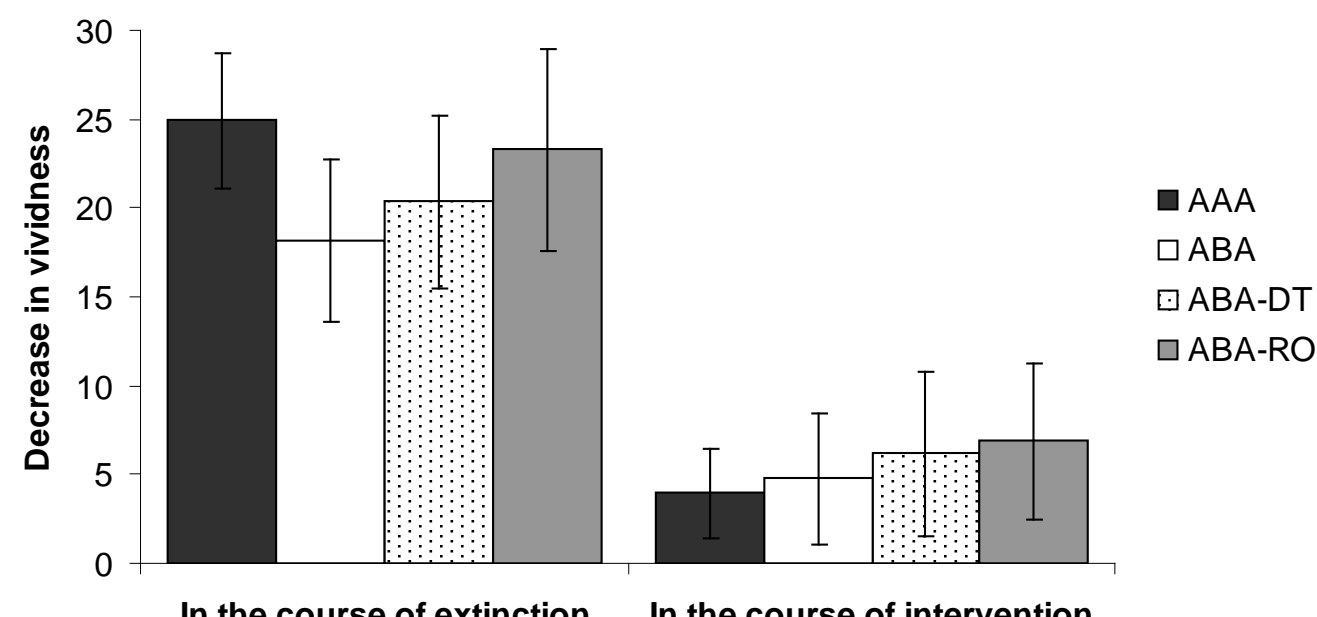

In the course of extinction In the course of intervention

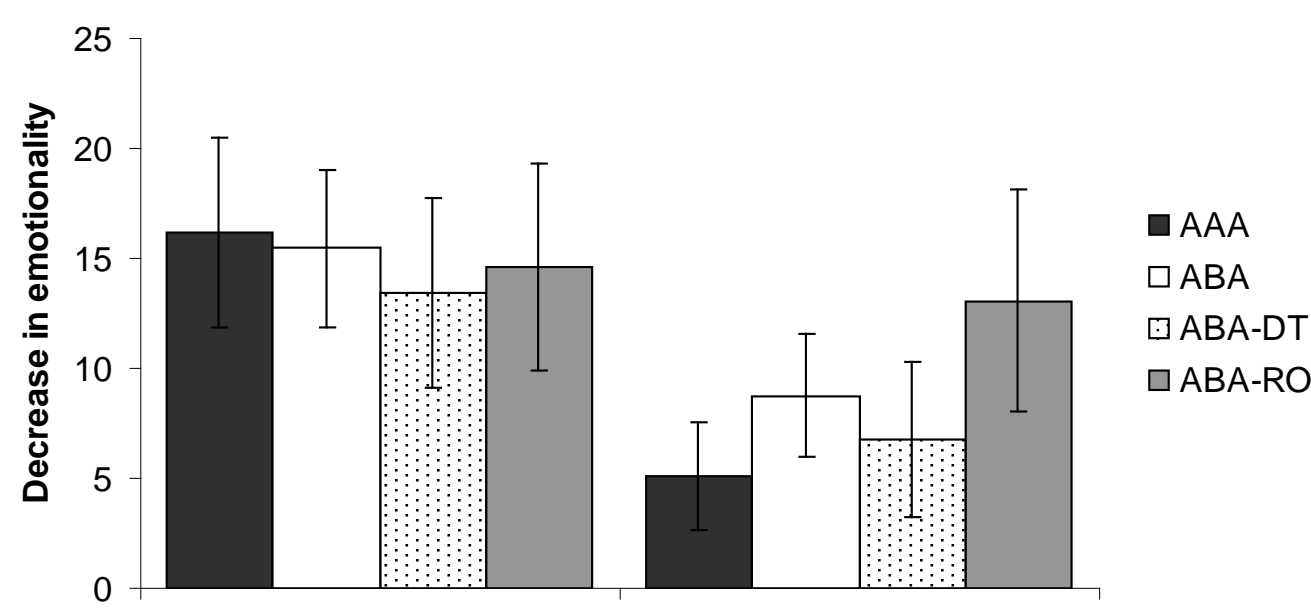

In the course of extinction In the course of intervention

Figure 2: Mean decrease in vividness and emotionality for each condition. Error bars reflect SEM.

Startle responses were analyzed for the two time points: (1) pre (i.e., after acquisition) and (2) post (i.e., after the test phase). Figure 3 illustrates the startle responses per condition. A 2 (Time: pre vs. post) $\times 4$ (Condition: AAA vs. ABA vs. ABA-DT vs. ABA-RO) ANOVA on blink magnitudes revealed a main effect of time, $F(1,76)=13.98, p<$ .001 , with startle responses decreasing over time. There was no significant main effect for condition, $F(3,76)=$ $1.49, p=.22$, and no interaction effect, $F<1$. To test the hypothesis that the dual-task reduced startle responses to the recalled US memory, a planned pairwise comparison was carried out between reductions in ABA-DT $(M=3.87$, $S D=5.66)$ and reductions in $A A A$ and $A B A$ together $(M=1.86, S D=6.26)$. Contrary to the hypothesis, the analyses did not show greater reductions in arousal in ABA-DT compared to the other conditions, $t(58)=1.20, p=$ .12 . 
Thus, the second hypothesis was not confirmed: there was no evidence that the dual-task reduced vividness, emotionality, or physiological responses to the US representation compared to merely recalling the US or fulfilling a filler task.

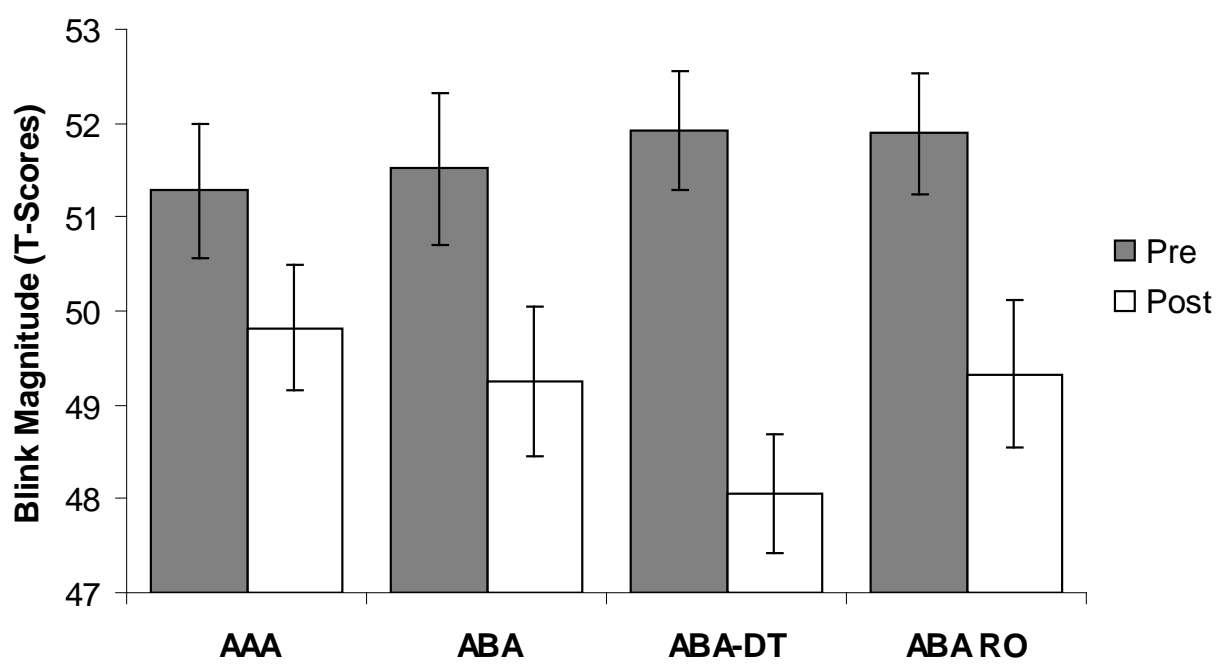

Figure 3: Mean blink magnitudes at the pre-intervention and post-intervention for each condition. Error bars reflect SEM.

\section{Discussion}

This study examined whether EM during recall of memory for an aversive US can reduce fear renewal. As predicted, dual-tasking was shown to attenuate the renewal of US-expectancy, compared to doing a filler task. Mere recall of the US did not attenuate fear renewal, but the renewal ratings in this condition did not significantly differ from those in the dual-task condition. No direct evidence was found, however, that the fear renewal attenuation effect was mediated by US-devaluation: decreases in vividness, emotionality, and startle responses over time did not differ between the conditions.

The results corroborate the findings by Dibbets et al. (2012), who showed a decrease in renewal of US-expectancy following IR during extinction. In the current study, the intervention (i.e., dual-task) was scheduled after extinction, thus ruling out that differences in fear renewal could be explained by differences in extinction. Dual-tasking, like IR, was considered to be a technique that may devaluate the US representation. However, the current study did not provide evidence for US devaluation actually taking place. Decreases in memory vividness, emotionality and startle potentiation were observed, but did not differ between conditions. This is inconsistent with earlier studies that demonstrated that recall with EM relative to mere recall leads to reductions in vividness and emotionality of images or autobiographical memories (e.g., Andrade et al., 1997; Gunter \& Bodner, 2008; Maxfield et al., 2008; van den Hout et al., 2011; van den Hout et al., 2001), as well as reductions in potentiated startle to imagery of aversive memories (e.g., Engelhard, van Uijen et al., 2010). It seems likely that this disparity is due to methodological differences. In earlier studies that reported beneficial effects of the dual task, participants typically recalled distressing autobiographical memories (e.g., Engelhard et al., 2011; Gunter \& Bodner, 2008; van den Hout et al., 2011). The present study is the first to our knowledge that integrates the dual task into a fear conditioning paradigm. As the conditioning procedure requires a-priori defined stimuli with fixed duration and exact presentation timing, we employed an aversive picture as the US. It may be assumed that personal memories selected for their unpleasantness are more aversive than the new, short-lived picture that was shown in the current study. Following the first US recall phase, 20 participants (25\%) rated the unpleasantness of their memory for the US below $50(0=$ not at all unpleasant, $100=$ extremely unpleasant), and 18 participants $(22.5 \%)$ rated the vividness of their memory for the US below $50(0=$ not at all vivid, $100=$ extremely vivid). Lower scores leave little room for decreases after the intervention. The present results therefore do not doubt the (clinical) efficacy of the dual task but rather the appropriateness of the current design to test its efficacy. 
Furthermore, it cannot be ruled out that reductions in memory vividness, emotionality, and startle potentiation were observed in all conditions because all participants underwent periods of US recall (for the assessment of memory vividness and emotionality) and therefore were potentially subject to the effects of US devaluation. However, habituation after such a brief exposure (144 $\mathrm{s}$ in the current study) may not be expected (for overview of studies, see Marks, 1987; p. 267-273).

As devaluation of the US representation cannot be brought forward as the mediating mechanism for reduced fear renewal, what can be? A recent study showed that EM during memory retrieval renders the memory less accessible (van den Hout, Bartelski, \& Engelhard, 2013). Participants that recalled an earlier presented image while making EM both reproduced and recognized less details of the image later on, compared to participants in a recall only condition (experiment 1 ). This finding was replicated with a reaction time task that assessed memory accessibility (experiment 2). Possibly, dual-tasking in the present study rendered the US representation less accessible. As a result, subsequent encounters with a CS+ may have evoked a much weaker US representation, thereby reducing US-expectancy (cf. the availability heuristic; Kahneman, Slovic, \& Tversky, 1982).

In sum, the present findings partly confirmed the hypotheses and raise important questions. First, we did not demonstrate US devaluation. The hypothesis that US devaluation reduces fear renewal thus still awaits critical testing. Second, we did observe reduced fear renewal. To test the hypothesis that fear renewal can be affected by memory accessibility, future studies may employ techniques that directly target memory accessibility. Due to these empirical questions we believe that, at present, any clinical implications are premature. If, however, corroborating evidence suggests that changes in the US memory or its accessibility can reduce fear renewal, then it might be possible to optimize traditional exposure-based treatment by adding techniques that directly target the US memory.

Several issues deserve further attention. First, it is unclear how the findings regarding merely recalling the US (ABA-RO) should be interpreted. Renewal scores did not differ from ABA and ABA-RO, which suggests that recall only did not attenuate fear renewal. At the same time, ABA-RO and ABA-DT did not differ, suggesting that dualtasking did not lead to significantly less renewal than recall only. Possibly, watching a fixed circle (ABA-RO) was not completely effortless, and slightly interfered with US recall. This may have rendered the US memory somewhat less accessible and may explain why renewal scores for ABA-RO were in between ABA and ABA-DT.

Next, on a physiological level, we did not observe fear acquisition, extinction or renewal, as only a minority of participants physiologically responded to the CSs. On the one hand, this lack of responding is not in line with studies that demonstrated differential SCR to aversive pictures (Dawson et al., 2007; Dibbets et al., 2012; Klucken et al., 2009), and may indicate that anticipation of the US was insufficiently arousing. On the other hand, the US actually resulted in a higher SCR than both CSs at the first presentation, suggesting that the US elicited a fear response. This agrees with findings by Dibbets et al. (2012), who used the same US, and also showed larger SCR to the US than to CS+ or CS- at first presentations. Furthermore, analyses on the available SCR data showed differential responding during the acquisition phase. Yet, considering the low response rate, it may be advised to employ a more aversive US in future studies, like a mild electric shock or loud tone (e.g., Ohman \& Mineka, 2001; Vansteenwegen et al., 2005).

Finally, Figure 1 shows a substantial increase in expectancy ratings for CS- during the first extinction trial. This may be explained by the instructions right before the extinction phase: participants were told that possible changes may occur in the CS-US relationship, which may have increased US-expectancy (a "better safe-than-sorry strategy"). Nevertheless, at the first extinction trial, expectancy ratings were still higher for CS+ than for CS-, $F(1$, 76) $=9.58, p<.01$, which did not differ across conditions, $F(3,76)=2.48, p=.07$, suggesting that conditioned discrimination transferred well across phases and contexts.

A limitation of this study involves the low physiological responding during anticipation of the US. Future studies may employ a US that is more typical for fear conditioning (e.g., electric shock or loud tone) or employ a design that impedes quick habituation to the US. Furthermore, mostly undergraduate females participated in this study, and it is unclear whether the findings may be generalized to other populations. The current findings need replication, but may serve as a starting point for future studies exploring the role of dual-tasks in preventing fear renewal.

In conclusion, this study explored a new way to counter the return of fear after extinction. The findings suggest that imagery of a US representation while conducting a taxing dual-task may attenuate the renewal of fear. 


\section{Acknowledgements}

This study was supported by a grant from the Netherlands Ministry of Defense and a Vidi innovational research grant from the Netherlands Organisation for Scientific Research (NWO) awarded to IME. The authors would like to thank Col-MD Kees ljzerman from the Netherlands Military Mental Health Care for support, and Meral Seyhan and Fardau Bosma for their assistance with data collection.

\section{References}

Andrade, J., Kavanagh, D., \& Baddeley, A. (1997). Eye-movements and visual imagery: A working memory approach to the treatment of post-traumatic stress disorder. British Journal of Clinical Psychology, 36, 209-223. http://dx.doi.org/10.1111/j.2044-8260.1997.tb01408.x

Balooch, S. B., \& Neumann, D. L. (2011). Effects of multiple contexts and context similarity on the renewal of extinguished conditioned behavior in an ABA design with humans. Learning and Motivation, 42, 53-63. http://dx.doi.org/10.1016/j.Imot.2010.08.008

Bisson, J. I., Ehlers, A., Matthews, R., Pilling, S., Richards, D., \& Turner, S. (2007). Psychological treatments for chronic post-traumatic stress disorder. British Journal of Psychiatry, 190, 97-104. http://dx.doi.org/10.1192/bjp.bp.106.021402

Blumenthal, T. D., Cuthbert, B. N., Filion, D. L., Hackley, S., Lipp, O. V., \& van Boxtel, A. (2005). Committee report: Guidelines for human startle eyeblink electromyographic studies. Psychophysiology, 42, 1-15. http://dx.doi.org/10.1111/i.1469-8986.2005.00271.x

Bouton, M. E. (2002). Context, ambiguity, and unlearning: sources of relapse after behavioral extinction. Biological Psychiatry, 52, 976-986. http://dx.doi.org/10.1016/j.bbr.2011.03.031

Bouton, M. E. (2004). Context and behavioral processes in extinction. Learning and Memory, 11, 485-494. http://dx.doi.org/10.1101//m.78804

Bouton, M. E., García-Gutiérrez, A., Zilski, J., \& Moody, E. W. (2006). Extinction in multiple contexts does not necessarily make extinction less vulnerable to relapse. Behavior Research and Therapy, 44, 983-994. http://dx.doi.org/10.1016/j.brat.2005.07.007

Bouton, M. E., \& King, D. A. (1983). Contextual control of the extinction of conditioned fear: tests for the associative value of the context. Journal of Experimental Psychology: Animal Behavior Processes, 9, 248-265. http://dx.doi.org/10.1037/0097-7403.9.3.248

Chambless, D. L., \& Ollendick, T. H. (2001). Empirically supported psychological interventions: controversies and evidence. Annual Review of Psychology, 52, 685-716. http://dx.doi.org/10.1146/annurev.psych.52.1.685

Craske, M. G., Kircanski, K., Zelikowsky, M., Mystkowski, J., Chowdhury, N. \& Baker, A. (2008). Optimizing inhibitory learning during exposure therapy. Behavior Research and Therapy, 46, 5-27. http://dx.doi.org/10.1016/i.brat.2007.10.003

Davey, G. C. L. (1997). A conditioning model of phobias. In: Phobias: a Handbook of Theory, Research and Treatment, ed. G. C. L. Davey, pp. 301-322. Chichester: Wiley.

Davey, G. C. L., \& McKenna, I. (1983). The effects of postconditioning revaluation of $\mathrm{CS}_{1}$ and UCS following pavlovian second-order electrodermal conditioning in humans. The Quarterly Journal of Experimental Psychology, 35, 125-133. doi:10.1080/14640748308400899

Dawson, M. E., Rissling, A. J., Schell, A. M., \& Wilcox, R. (2007). Under what conditions can human affective conditioning occur without contingency awareness? Test of the evaluative conditioning paradigm. Emotion, 7 , 755-766. http://dx.doi.org/10.1037/1528-3542.7.4.755

Dawson, M. E., Schell, A. M., \& Filion, D. L. (2000). The electrodermal system. In J. T. Cacioppo, L. G. Tassinary, \& G. G. Berntson (Eds.), Principles of Psychophysiology: Physical, Social, and Inferential Elements (pp. 200223). Cambridge, UK: Cambridge University Press.

De Houwer, J., Thomas, S., \& Baeyens, F. (2001). Associative learning of likes and dislikes: A review of 25 years of research on human evaluative conditioning. Psychological Bulletin, 127, 853-869. http://dx.doi.org/10.1037//0033-2909.127.6.853

Deacon, B. J., \& Abramowitz, J. S. (2004). Cognitive and behavioral treatments for anxiety disorders: a review of meta-analytic findings. Journal of Clinical Psychology, 60, 429-441. http://dx.doi.org/10.1002/jclp.10255 
Delamater, A. R. (1996). Effects of several extinction treatments upon the integrity of Pavlovian stimulus-outcome associations. Learning and Behavior, 24, 437-449. http://dx.doi.org/10.3758/BF03199015

Delamater, A. R. (2004). Experimental extinction in Pavlovian conditioning: behavioural and neuroscience perspectives. The Quarterly Journal of Experimental Psychology, 57, 97-132. http://dx.doi.org/10.1080/02724990344000097

Dibbets, P., \& Maes, J. H. R. (2011). The effect of an extinction cue on ABA-renewal: Does valence matter? Learning and Motivation, 42, 133-144. http://dx.doi.org/10.1016/j.Imot.2010.12.003

Dibbets, P., Poort, H., \& Arntz, A. (2012). Adding imagery rescripting during extinction leads to less ABA renewal. Journal of Behavior Therapy and Experimental Psychiatry, 43, 614-624. http://dx.doi.org/10.1016/.j.jbtep.2011.08.006

Effting, M., \& Kindt, M. (2007). Contextual control of human fear associations in a renewal paradigm. Behavior Research and Therapy, 45, 2002-2018. http://dx.doi.org/10.1016/j.brat.2007.02.011

Engelhard, I. M., van den Hout, M. A., Janssen, W., \& van der Beek, J. (2010). Eye movements reduce the vividness and emotionality of "flashforwards". Behavior Research and Therapy, 48, 422-447. http://dx.doi.org/10.1016/j.brat.2010.01.003

Engelhard, I. M., van den Hout, M. A., \& Smeets, M. A. M. (2011). Taxing working memory reduces vividness and emotional intensity of images about the Queen's Day tragedy. Journal of Behavior Therapy and Experimental Psychiatry, 42, 32-37. http://dx.doi.org/10.1016/i.jbtep.2010.09.004

Engelhard, I. M., van Uijen, S. L., \& van den Hout, M. A. (2010). The impact of taxing working memory on negative and positive memories. European Journal of Psychotraumatology, 1, 5623. http://dx.doi.org/10.3402/ejpt.v1i0.5623

Eysenck, H. J., \& Eysenck, S. B. G. (1975). Manual of the Eysenck Personality Questionnaire. New York: Hodder \& Stoughton.

Eysenck, H. J., \& Martin, I. (1987). Theoretical Foundations of Behavior Therapy. New York: Plenum Press. http://dx.doi.org/10.1007/978-1-4899-0827-8

Fava, G. A., Rafanelli, C., Grandi, S., Conti, C., Ruini, C., Mangelli, L., \& Belluardo, P. (2001). Long-term outcome of panic disorder with agoraphobia treated by exposure. Psychological Medicine, 31, 891-898. http://dx.doi.org/10.1017/S0033291701003592

Fava, G. A., Grandi, S., Rafanelli, C., Ruini, C., Conti, S., \& Belluardo, P. (2001). Long-term outcome of social phobia treated by exposure. Psychological Medicine, 31, 899-905. http://dx.doi.org/10.1017/S0033291701003592

Fowles, D. C., Christie, M. J., Edelberg, R., Grings, W. W., Lykken, D. T., \& Venables, P. H. (1981). Publication recommendations for electrodermal measurements. Psychophysiology, 18, 232-239. http://dx.doi.org/10.1111/j.1469-8986.1981.tb03024.x

Grillon, C., \& Baas, J. (2003). A review of the modulation of the startle reflex by affective states and it application in psychiatry. Clinical Neurophysiology, 114, 1557-1579. http://dx.doi.org/10.1016/S1388-2457(03)00202-5

Grillon, C., Pine, D. S., Baas, J. M. P., Lawley, M., Ellis, V., \& Charney, D. S. (2006). Cortisol and DHEA-S are associated with startle potentiation during aversive conditioning in humans. Psychopharmacology, 186, 434441. http://dx.doi.org/10.1007/s00213-005-0124-2

Gunter, R. W., \& Bodner, G. E. (2008). How eye movements affect unpleasant memories: support for a workingmemory account. Behavior Research and Therapy, 46, 913-931. http://dx.doi.org/10.1016/i.brat.2008.04.006

Hermans, D., Craska, M. G., Mineka, S., \& Lovibond, P. F. (2006). Extinction in human fear conditioning. Biological Psychiatry, 60, 361-368. http://dx.doi.org/10.1016/j.biopsych.2005.10.006

Hofmann, S. G., \& Smits, J. A. J. (2008). Cognitive-behavioral therapy for adult anxiety disorders: a meta-analysis of randomized placebo-controlled trials. Journal of Clinical Psychiatry, 69, 621-632. http://dx.doi.org/10.4088/JCP.v69n0415

Holmes, E. A., \& Mathews, A. (2010). Mental imagery in emotion and emotional disorders. Clinical Psychology Review, 30, 349-362. http://dx.doi.org/10.1016/j.cpr.2010.01.001

Jones, T., \& Davey, G. C. L. (1990). The effects of cued UCS rehearsal on the retention of differential 'fear' conditioning: An experimental analogue of the 'worry' process. Behavior Research and Therapy, 28, 159-164. http://dx.doi.org/10.1016/0005-7967(90)90028-H 
Kahneman, D., Slovic, P., \& Tversky, A. (1982). Judgment under uncertainty: Heuristics and biases. New York: Cambridge University Press. http://dx.doi.org/10.1017/CBO9780511809477

Klucken, T., Kagerer, S., Schweckendiek, J., Tabbert, K., Vaitl, D., \& Stark, R. (2009). Neural, electrodermal and behavioral response patterns in contingency aware and unaware subjects during a picture-picture conditioning paradigm. Neuroscience, 158, 721-731. http://dx.doi.org/10.1016/j.neuroscience.2008.09.049

Lee, C. W., \& Cuijpers, P. (2013). A meta-analysis of the contribution of eye movements in processing emotional memories. Journal of Behavior Therapy and Experimental Psychiatry, 44, 231-239. http://dx.doi.org/10.1016/j.jbtep.2012.11.001

Lipp, O. V. (2006). Human fear learning: Contemporary procedures and measurement. In M.G. Craske, D. Hermans \& D. Vansteenwegen (Eds.), Fear and Learning: From basic processes to clinical implications (pp. 3752). Washington, DC: American Psychological Association. http://dx.doi.org/10.1037/11474-002

Lissek, S., Powers, A. S., McClure, E. B., Phelps, E. A., Woldehawariat, G., Grillon, C., \& Pine, D. S. (2005). Classical fear conditioning in the anxiety disorders: a meta-analysis. Behavior Research and Therapy, 43, 13911424. http://dx.doi.org/10.1016/i.brat.2004.10.007

Lykken, D. T., \& Venables, P. H. (1971). Direct measurement of skin conductance: a proposal for standardization. Psychophysiology, 8, 656-672. http://dx.doi.org/10.1111/j.1469-8986.1971.tb00501.x

Marks, I. M. (1987). Fears, phobias and rituals. Panic, anxiety and their disorders. Oxford University Press.

Maxfield, L., Melnyk, W. T., \& Hayman, C. A. G. (2008). A working memory explanation for the effects of eye movements in EMDR. Journal of EMDR Practice and Research, 2, 247-261. http://dx.doi.org/10.1891/19333196.2.4.247

Mineka, S., Mystkowski, J. L., Hladek, D., \& Rodriguez, B. I. (1999). The effects of changing contexts on return of fear following exposure therapy for spider fear. Journal of Consulting and Clinical Psychology, 67, 599-604. http://dx.doi.org/10.1037/0022-006X.67.4.599

Mineka, S., \& Oehlberg, K. (2008). The relevance of recent developments in classical conditioning to understanding the etiology and maintenance of anxiety disorders. Acta Psychologica, 127, 567-580. http://dx.doi.org/10.1016/i.actpsy.2007.11.007

Miller, M. W., Patrick, C. J., \& Levenston, G. K. (2002). Affective imagery and the startle response: Probing mechanisms of modulation during pleasant scenes, personal experiences, and discrete negative emotions. Psychophysiology, 39, 519-529. http://dx.doi.org/10.3402/ejpt.v1i0.5623

Mystkowski, J. L., Craske, M. G., \& Echiverri. A. M., (2002). Treatment context and return of fear in spider phobia. Behavior Therapy, 33, 399-416. http://dx.doi.org/10.1016/S0005-7894(02)80035-1

Neumann, D. L., \& Kitlertsirivatana, E. (2010). Exposure to a novel context after extinction causes a renewal of extinguished conditioned responses: implications for the treatment of fear. Behavior Research and Therapy, 48, 565-570. http://dx.doi.org/10.1016/i.brat.2010.03.002

Ohman, A., \& Mineka, S. (2001). Fears, phobias, and preparedness: toward an evolved module of fear and fear learning. Psychological Review, 108, 483-522. http://dx.doi.org/10.1037//0033-295X.108.3.483

Pineles, S. L., Orr, M. R., \& Orr, S. P. (2009). An alternative scoring method for skin conductance responding in a differential fear conditioning paradigm with a long-duration conditioned stimulus. Psychophysiology, 46, 984995. http://dx.doi.org/10.1111/j.1469-8986.2009.00852.x

Rauhut, A. S., Thomas, B. L., \& Ayres, J. J. B. (2001). Treatments that weaken Pavlovian conditioned fear and thwart its renewal in rats: implications for treating human phobias. Journal of Experimental Psychology: Animal Behavior Processes, 27, 99-114. http://dx.doi.org/10.1037/0097-7403.27.2.99

Rescorla, R. A. (1996). Preservation of Pavlovian associations through extinction. The Quarterly Journal of Experimental Psychology, 49, 245-258.

Sanderman, R., Arrindell, W. A., Ranchor, A. V., Eysenck, H. J., \& Eysenck, S. B. G. (1995). Het meten van de persoonlijkheidskenmerken met de Eysenck Personality Questionnaire (EPQ). Een handleiding. Groningen, the Netherlands: University of Groningen, Northern Centre for Healthcare Research.

Simpson, H. B., Liebowitz, M. R., Foa, E. B., Kozak, M. J., Schmidt A. B.,... Campeas, R. (2004). Post-treatment effects of exposure therapy and clomipramine in obsessive-compulsive disorder. Depression and Anxiety, 19, 225-233. http://dx.doi.org/10.1002/da.20003

Spielberger, C. D., Gorsuch, R. L., \& Lushene, R. E. (1970). Manual for the State-Trait Anxiety Inventory. Palo Alto, CA: Consulting Psychologist Press. 
Van den Hout, M.A., Bartelski, N., \& Engelhard, I.M. (2013). On EMDR: eye movements during retrieval reduce subjective vividness and objective memory accessibility during future recall. Cognition \& Emotion, 27, 177-183. http://dx.doi.org/10.1080/02699931.2012.691087

Van den Hout, M. A., Engelhard, I. M., Rijkeboer, M. M., Koekebakker, J., Hornsveld, H., Leer, A.,... Akse, N. (2011). EMDR: Eye movements superior to beeps in taxing working memory and vividness of recollections. Behavior Research and Therapy, 49, 92-98. http://dx.doi.org/10.1016/j.brat.2010.11.003

Van den Hout, M., Muris, P., Salemink, E., \& Kindt, M. (2001). Autobiographical memories become less vivid and emotional after eye movements. British Journal of Clinical Psychology, 40, 121-130. http://dx.doi.org/10.1348/014466501163571

Van der Ploeg, H. M., Defares, P. B., \& Spielberger, C. D. (1980). Handleiding bij de Zelfbeoordelings Vragenlijst (ZBV). Lisse: Swets and Zeitlinger.

Vansteenwegen, D., Hermans, D., Vervliet, B., Francken, G., Beckers, T., Baeyens, F., \& Eelen, P. (2005). Return of fear in a human differential conditioning paradigm caused by a return to the original acquisition context. Behavior Research and Therapy, 43, 323-336. http://dx.doi.org/10.1016/j.brat.2004.01.001

Vansteenwegen, D., Vervliet, B., Hermans, D., Beckers, T., Baeyens, F., \& Eelen, P. (2006). Stronger renewal in human fear conditioning when tested with an acquisition retrieval cue than with an extinction retrieval cue.

Behaviour Research and Therapy, 44, 1717-1725. http://dx.doi.org/10.1016/i.brat.2005.10.014

Vansteenwegen, D., Vervliet, B., Iberico, C., Baeyens, F., van den Bergh, O., \& Hermans, D. (2007). The repeated confrontation with videotapes of spiders in multiple contexts attenuates renewal of fear in spider-anxious students. Behavior Research and Therapy, 45, 1169-1179. http://dx.doi.org/10.1016/j.brat.2006.08.023 